\title{
Raising Professional Presence Through Team Leadership in the Critical Care Setting
}

Identifying meaningful ways of raising our professional presence as respiratory therapists (RTs) in the health-care sector is certainly on the minds and agendas of our profession's leaders in several tangible ways. The comprehensive premise of Creating a Vision for Respiratory Care in 2015 and Beyond launched by the American Association for Respiratory Care (AARC) executive office began with the formation of a task force that led to the first conference being held March 3-5, 2008, in Dallas, Texas, with the second and third conferences conducted in 2009 and 2010, respectively. Through the meetings of this task force, competencies have been quantified and prioritized, models have been debated and proposed, and methods have been examined and recommended for advancing graduate therapists and the RT workforce for 2015. ${ }^{1-3}$ And here we are.

Advancing our professional presence in health care is certainly beyond the assessment of clinical skills and competencies associated with the RRT credential and national board exams. One might make a case that the tools needed to advance our professional presence in the workplace actually come down to the level of leadership and communication skills taught in RT programs. As therapists, we witness daily opportunities in the patient care setting to demonstrate team leadership, whether those opportunities are realized or not. Although the specific assessment of leadership and communication skills is not part of our national credentialing exam, these principal elements are appropriately required to be included in the curricula of all RT programs as mandated by our educational accreditation agency. Granted, some may deem these skills only as enrichment components of the educational process; however, most managers, educators, and practitioners would agree that the skill set associated with leadership and communication is indeed among those essential elements re-

Dr Marshall has disclosed no conflicts of interest.

Correspondence: S Gregory Marshall PhD RRT RPSGT RST, Department of Respiratory Care, College of Health Professions, Texas State University, 601 University Drive, San Marcos, TX 78666-4684. E-mail: sm10@txstate.edu.

DOI: $10.4187 /$ respcare. 03978 quired for advancing a professional presence in most every health-care venue.

In projecting the vision for the RT's leadership role, Kacmarek et $\mathrm{al}^{1}$ proposed that "care teams will become the standard for health-care delivery in and outside the hospital" and that "team members will have different roles

See the Original Study on Page 321

and responsibilities at different times, but respect and collaboration will be the hallmark of effective team function." In delineating the competencies needed by graduate RTs in 2015, Barnes et $\mathrm{al}^{2}$ stated that care teams "may frequently be led by therapists." In the recommendations for transitioning the RT workforce, Barnes et al $^{3}$ suggested that "all RTs will be consultants on how respiratory care should be provided," with a primary responsibility on patient rounds in which "RTs are expected to contribute to the discussion of goals and direction of therapy and to provide evidence supporting various approaches to respiratory care used in the intensive care unit."

In his publication entitled Mechanical Ventilation Competencies of the Respiratory Therapist in 2015 and Beyond, Kacmarek ${ }^{4}$ interjected an unlikely pearl of advice on communication and teamwork regarding mechanical ventilation and the competencies of the ICU therapist. He stated, "The key to collaborative function of any clinician in critical care is effective communication and teamwork." Kacmarek discussed how the competent ICU therapist in 2015 and beyond should present respiratory/ventilatorspecific information during ICU rounds and be an active part of establishing the daily care plan for patients. He suggests that "the RT should be able to effectively argue for a specific approach to ventilatory support and always function as a patient advocate." Understanding that communication is actually an essential competency in the management of ventilated patients and what is expected of the ICU therapist to function as a team member and team leader in the ICU are key to developing a culture of teamwork and collaboration between all ICU team members. ${ }^{4}$

The creation of care teams with members from different disciplines is the primary premise behind interprofessional education and practice and has been a theme in the literature over the last 20 years. The key factors associated 
with interprofessional practice include integrated care, team approach (through training and education), communication, and respect. ${ }^{5}$ The new discussions regarding interprofessional practice revolve around issues related to reducing medical errors. The Institute of Medicine's pivotal report in 2000, To Err is Human: Building a Safer Health System, exposed the fragmentation of our health-care system by reporting that medical errors may represent the third leading cause of death in the United States. ${ }^{6}$ The report clearly identified miscommunication among providers as a key factor leading to medication errors.

In this issue of Respiratory CARE, Genet et $\mathrm{al}^{7}$ describe interdisciplinary rounds in the neonatal ICU (NICU) led by RTs and designed to establish and communicate patient care goals and monitor patient progress between healthcare providers. The authors hypothesized improvement in staff satisfaction, execution of orders within $30 \mathrm{~min}$ of order entry into the electronic medical record, and communication of complete and accurate information during rounds between members of the interdisciplinary team. NICU nurses, RTs, nurse practitioners, residents, and attending physicians were identified as members of the interdisciplinary team participating in the study. In addition to established multidisciplinary rounds conducted in the NICU each morning, the interdisciplinary team rounds led by the RT in this study were implemented each morning at the beginning of the 7:00 AM shift. A reporting tool was developed by a core team of RTs and neonatologists to facilitate a consistent presentation of clinical information to the interdisciplinary team. The interdisciplinary round program led by RTs was launched following pilot testing of the rounding tool and educational in-service sessions introducing the NICU therapists to the rounding tool and the responsibilities of leading rounds.

Process data were collected at 2 intervals through direct observation of the rounding process and electronic medical record review. Six months following implementation of the rounds, a survey was conducted to evaluate the interdisciplinary team's perception of the program and to evaluate timely order entry. More than three quarters of the interdisciplinary round team members surveyed perceived rounds led by the RT as improving communication among interdisciplinary team members in addition to improving staff morale. Not only did team members perceive an improved timeliness in order entry and execution of respiratory care-related orders, but statistical analysis confirmed a significant decrease in the amount of time for order entry and order implementation as documented through the electronic medical record. The interdisciplin- ary team rated both collaboration and communication very high as a result of the rounds that were led by the RT.

Although the issue of elevating professional presence of the RT through team leadership was not the primary focus, Genet et $\mathrm{al}^{7}$ should be applauded for bringing the issue of RT team leadership to the forefront in a practical, patientcentered demonstration of knowledge and skill to their NICU teammates. This example of the RT team taking the initiate to increase communication through leadership is outstanding. The ripple effect of the leadership initiative taken in this NICU has changed the climate of teamwork and morale in their unit in a very powerful, tangible way that results in better patient care, a more enjoyable work environment, and the sense of community that all healthcare teams desire to foster. While we are debating issues such as raising the professional presence of respiratory therapy in the health-care sector, the opportunities to demonstrate leadership and initiative as health-care professionals already exist around us in many aspects of respiratory care education, research, management, and clinical practice. Let's show the rest of the health-care team what we've got and bring it ... carpe diem!

S Gregory Marshall PhD RRT RPSGT RST

Department of Respiratory Care College of Health Professions Texas State University San Marcos, Texas

\section{REFERENCES}

1. Kacmarek RM, Durbin CG, Barnes TA, Kageler WV, Walton JR, O'Neil EH. Creating a vision for respiratory care in 2015 and beyond. Respir Care 2009;54(3):375-389.

2. Barnes TA, Gale DD, Kacmarek RM, Kageler WV. Competencies needed by graduate respiratory therapists in 2015 and beyond. Respir Care 2010;55(5):601-616.

3. Barnes TA, Kacmarek RM, Kageler WV, Morris MJ, Durbin CG. Transitioning the respiratory therapy workforce for 2015 and beyond. Respir Care 2011;56(5):681-690.

4. Kacmarek RM. Mechanical ventilation competencies of the respiratory therapist in 2015 and beyond. Respir Care 2013;58(6):10871096.

5. Interprofessional Education Collaborative Expert Panel. Core competencies for interprofessional collaborative practice: report of an expert panel. Washington, DC: Interprofessional Education Collaborative; 2011.

6. Institute of Medicine. To err is human: building a safer health system. In: Kohn LT, Corrigan JM, Donaldson MS. Washington, DC: National Academies Press; 2000.

7. Genet IC, Firestone KS, Volsko TA. Neonatal respiratory therapistled rounds can improve staff satisfaction and timeliness of respiratory interventions. Respir Care 2015;60(3):321-327 